\title{
Post Operative Shivering: Prophylactic Effects of Ketamine and Pethidine, A Comparative Study in Tertiary Care Hospital.
}

\author{
Dr. Ramalingaraju.A.V.S ${ }^{1}$, Dr. Siva Ranjan. D $^{2}$, \\ Dr. M. Neethika ${ }^{3}$ \\ ${ }^{I}$ Associate Professor, Department of anaesthesia, Malla Reddy Institute of Medical Sciences, India \\ ${ }^{2}$ Assistant Professor, Department of Pathology, Apollo Institute of Medical Sciences \& Research, India \\ ${ }^{3}$ Junior Resident, Department of Dentistry, India
}

\begin{abstract}
Introduction: Postanesthetic shivering is one of the common problems following general anesthesia and an accompanying part of general anesthesia with different unpleasant and stressful consequences for patients undergoing surgery. Postoperative shivering may lead

to multiple complications. Hence, its proper management is necessary for both treatment and prevention. This study aim was to compare the prophylactic effects of ketamine and pethidine in preventing postoperative shivering in general anesthesia.

Methods: In this prospective study, patients aged from 21 years to 72 years were taken for study who has been scheduled for elective surgery under general anesthesia and they were randomized into two groups. Each group received intravenous (IV) pethidine, and IV ketamine. The frequency of shivering was determined immediately after surgery, and at 10.20. And 30 minutes,
\end{abstract} postoperatively.

Results: Each group included 27 patients. Mean values of central temperature in the recovery room were significantly different between the 2 groups $(p<0.05)$. However, the differences were not significant during

surgery but Postoperative shivering was reported in $14.9 \%$ and $3.7 \%$ of patients in ketamine and pethidine groups,

Conclusions: The result of this study showed that

Ketamine and Pethidine might reduce postoperative shivering . pethidine seems to be the most appropriate choice for preventing postoperative shivering.

Keywords: Ketamine; Pethidine, Postoperative shivering, general anesthesia.

\section{Introduction}

post operative Shivering is an unpleasant postoperative feeling that might be associated with adverse effects especially in patients with poor myocardial reserve. Postoperative shivering is one of the most common problems in the early recovery phase following general anesthesia.[1] It is considered as the sixth most important problem of current clinical anesthesiology with an estimated rate of 5- 65\%.[2,3]

It is the rhythmic contraction of muscles with frequency of 4-8 Hertz [4]. It is the natural response of the body to central hypothermia with release of cytokines from surgical site. It can also occur because of pain Almost all anesthetics impair autonomic control of body temperature. Its incidence ranges from 5\% to 65\% following general anesthesia and 30\% with epidural anesthesia [5, 6]. However, the incidence appears to be less as more patients are kept normothermic and opioids are administered more frequently and in larger doses than in the past. Shivering decreases mixed venous oxygen saturation as a result of impaired cardiopulmonary function. In addition, postoperative shivering can increase oxygen consumption up to 5 times, might increase carbon dioxide production, minute ventilation, and hence, cardiac output even in healthy adults [7].

It is a potentially serious complication that increases oxygen consumption roughly $100 \%$ in proportion to intraoperative heat loss. It might also be associated with increased blood pressure, intracranial pressure, metabolic rate, lactic acidosis, and postoperative surgical wound pain $[8,9]$.

Ketanserin, sufentanil, alfentanil, tramadol, physostigmine, clonidine, magnesium sulfate, Pethidine, dexamethasone, and doxaperam have been used for the treatment of postoperative shivering [10]. Among these, Pethidine is widely used as the first line therapy $[11,12]$. However, it might result in nausea and vomiting, delayed gastric emptying, and increased length of recovery stay. $\mathrm{N}$ methy $\mathrm{D}$ aspartate agonists including Ketamine can affect temperature regulation and might be effective for the management of shivering. Nevertheless, they are associated with some neuropsychological adverse effects including somnolence and hallucination. 
Since postanesthetic shivering is an accompanying part of general anesthesia with different unpleasant and stressful consequences for patients undergoing surgery, it seems that its proper management is necessary for both treatment and prevention. The purpose of this study was to compare Pethidine and Ketamine in the prevention of postoperative shivering in patients undergoing general anesthesia. The main outcome is to compare the incidence of postoperative shivering.

\section{Methods}

In this prospective study patients aged between 21 years to 72 years who were scheduled for elective surgery under general anesthesia at tertiary care hospital were enrolled. The patients and the investigators were blind to the study. They were randomly allocated (using randomization table) to receive either Pethidine 20mg $(\mathrm{n}=27)$, Ketamine $0.5 \mathrm{mg} / \mathrm{kg}(\mathrm{n}=27)$. Patients with a history of convulsions, hypersensitivity reaction to ketamine, and pethidine, history of using tricyclic antidepressants (TCAs), monoamine oxidase (MAO) inhibitors, and $\beta$ - blockers, multiple allergies, hypertension, coronary artery disease, dysautonomia, and other cardiorespiratory or neuromuscular pathology were excluded from the study. In addition, patients who received intraoperative blood component transfusion, and surgeries lasting more than 3 hours were excluded.

After receiving midazolam $0.05 \mathrm{mg} / \mathrm{kg}$ and fentanyl $2 \mathrm{~g} / \mathrm{kg}$, anesthesia was induced with propofol 2 $\mathrm{mg} / \mathrm{kg}$ and atracurium $0.5 \mathrm{mg} / \mathrm{kg}$ for endotracheal intubation. Anesthesia was maintained with propofol 70$00 \mu \mathrm{g} / \mathrm{kg} / \mathrm{min}$ and $\mathrm{N} 2 \mathrm{O} 50 \%$ in oxygen. Fentanyl was given $0.02 \mu \mathrm{g} / \mathrm{kg} / \mathrm{min}$. The room temperature and the intravenous fluids were kept between 22 to 24 centigrade degrees. Postoperative shivering was assessed immediately after surgery, and at 10, 20, and 30 minutes using the following scales: Grade 0: no shivering. Grade 1: slight fasciculation in the neck and face. Grade 2: visible shivering in more than one muscle group

Grade 3: shivering and movement throughout the body.

We used independent Student $t$-test and ANOVA to compare continuous variables exhibiting normal distribution, and Chi-square and Mann-Whitney $U$ test for non-continuous variables. $P$ value less than 0.05 was considered significant. In cases with a grade 3 shivering for more than 4 minutes, the prophylaxis was considered ineffective and $25 \mathrm{mg}$ IV pethidine was administered. Moreover, mean heart rate, mean arterial pressure (MAP), drug side effects, level of consciousness in the recovery room, and duration of extubation were evaluated and recorded.

Side effects of the studied drugs including hallucinations, agitation, blurred vision, drowsiness, nausea, vomiting, hypotension, tachycardia, meiosis, seizure, urinary retention, numbness, dry mouth and dizziness were recorded.

\section{Results}

Out of 54 patients who were taken for the study was aged from 21 years to 72 years with mean age of 46.5 years and weight of $63 \mathrm{~kg}$. There was also no significant difference among the groups with respect to ASA class and duration of surgery ( $\mathrm{p}$ values 0.07 and 0.1 respectively). Shivering was seen immediately after surgery in two groups.

Immediately after surgery shivering with grade $0,1,2$, and 3 in the ketamine group shivering was seen in 25,1,0, and 1 cases, and in the pethidine group 26,0, 0, 1 case shown in (table 1). Using Post-hoc ANOVA (Tuky test) revealed that the difference was between the first and the second groups ( $\mathrm{p}$ value $<0.01$ ). However, comparison of the Pethidine and Ketamine groups did not show significant difference ( $p$ value 0.15 ). Shivering was seen more commonly in the ketamine group than the pethidine group at 10 minutes (table 2). and at 20 as well in (table 3 ). No shivering cases were seen after 30 minutes of surgery in both the groups which is shown in (table 4).

Table : 1 .frequency of shivering in groups immediately after surgery

\begin{tabular}{|l|l|l|}
\hline & ketamine & Pethidine \\
\hline Grade 0 & 25 & 26 \\
\hline Grade 1 & 2 & 0 \\
\hline Grade 2 & 1 & 0 \\
\hline Grade 3 & 1 & 1 \\
\hline
\end{tabular}

Table :2 frequency of shivering in groups at 10 minutes after surgery

\begin{tabular}{|l|l|l|}
\hline & ketamine & Pethidine \\
\hline Grade 0 & 25 & 26 \\
\hline Grade 1 & 2 & 1 \\
\hline Grade 2 & 0 & 0 \\
\hline Grade 3 & 0 & 0 \\
\hline
\end{tabular}


Table :3 frequency of shivering in groups at 20 minutes after surgery

\begin{tabular}{|l|l|l|}
\hline & ketamine & Pethidine \\
\hline Grade 0 & 26 & 27 \\
\hline Grade 1 & $\mathbf{1}$ & $\mathbf{0}$ \\
\hline Grade 2 & $\mathbf{0}$ & $\mathbf{0}$ \\
\hline Grade 3 & $\mathbf{0}$ & $\mathbf{0}$ \\
\hline
\end{tabular}

Table :4 frequency of shivering in groups at 30 minutes after surgery

\begin{tabular}{|l|l|l|}
\hline & ketamine & Pethidine \\
\hline Grade 0 & 27 & 27 \\
\hline Grade 1 & 0 & 0 \\
\hline Grade 2 & 0 & 0 \\
\hline Grade 3 & 0 & 0 \\
\hline
\end{tabular}

\section{Discussion}

In this study, prophylactic effects of ketamine and pethidine in preventing postoperative shivering in general anesthesia were compared. Most anesthetics can decrease thermoregulation thresholds resulting in hypothermia in patients exposing to the operating room. Hypothermia may lead to shivering, prolonged drug action, coagulopathy, and decreased resistance to infection. Therefore, maintaining normal body temperature is pivotal for prevention of hypothermia and its complications.

Many studies have confirmed the effectiveness of pethidine in preventing postoperative shivering. The anti- shivering mechanism of pethidine is due to its action via $k$ receptor rather than $\mu$ opioid receptors.[13] However, pethidine has some adverse effects which limit its use in some cases. It may cause respiratory depression especially in patients with previous history of opioids and anesthetics administration. Other side effects are hypotension, postoperative nausea and vomiting.[14] Therefore, it seems that proper alternatives should be determined for cases with contraindications for pethidine administration.

Similar to the present study Pazuki et al revealed that Pethidine could better reduce postoperative shivering after cesarean section [15]. In another survey, it was reported that Pethidine and dexamethasone were similar in reducing shivering after abdominal surgery [16].

A few other studies have shown ketamine to have proper effects in preventing postoperative shivering. Some studies have also investigated different doses of the drug.[17,18] Dal et al. indicated low dose of ketamine $(0.5 \mathrm{mg} / \mathrm{kg})$ approximately 20 minutes before completion of surgery under general anesthesia, which was also administered in the current study, to be effective in preventing postoperative shivering. They concluded that ketamine can be used as an alternative prophylaxis for preventing postoperative shivering in patients with bradycardia, hypotension, respiratory depression, nausea, vomiting, and allergic reactions to pethidine.[18]

In contrast to our study, Ketamine has been effective in preventing shivering after prostate [19] and general surgeries [20]. Application of Ketamine and Pethidine in children after tonsillectomy showed the same result with no significant difference between the two drugs [21].In a recent study in Nigeria, the effectiveness of prophylactic low- dose of ketamine in preventing postoperative shivering has been reported.[22] Likewise, Norouzi et al. determined the optimum dose of ketamine for preventing postanesthetic shivering as 0.5 $\mathrm{mg} / \mathrm{kg}$.[23]

Postoperative shivering increases recovery length of stay and cost and is an additional burden to both the patients and hospitals. A number of studies showed the same result of efficacy of Pethidine and Ketamine in preventing postoperative shivering [24-28].

In addition to common drugs, many researchers have used tramadol, clonidine, dexamethasone , dexmedetomidine, acupuncture , ondansetron , for Prevention Of Postoperative Shivering. [ 29-36]

To conclude, considering the rates and severity of shivering, it seems that, as reported by previous studies and present study it shows that pethidine is the most appropriate choice for treatment and preventing postoperative shivering.

\section{References}

[1] Piper SN, Rohm KD, Suttner SW, Maleck WH, Kranke P, Boldt J. A comparison of nefopam and clonidine for the prevention of postanaesthetic shivering: a comparative, doubleblind and placebo-controlled dose-ranging study. Anaesthesia 2004; 59(6): 559-64.

[2] Macario A, Weinger M, Truong P, Lee M. Which clinical anesthesia outcomes are both common and important to avoid? The perspective of a panel of expert anesthesiologists. Anesth Analg[1999; 88(5): 1085-91.

[3] Roy JD. Postoperative shivering. Anesthesiology Rounds 2004;3(6): 56-60.

[4] Macario A, Weinger M, Carney S, Kim A. Which clinical anesthesia outcomes are important to avoid? The perspective of patients. Anesth Analg. 1999; 89(3): 625-8.

[5] Dabir SH, Radpey BAZ, Parsa T. Evaluation of the incidence of postane-sthesia shivering. Journal of Iranian Society Anaesthesiology and Intensive Care. 2006; 28(1): 60-9.

[6] Eberhart LH, Döderlein F, Eisenhardt G, Kranke P,Sessler DI, Torossian, et al. Independent risk factors for postoperative shivering. Anesth Analg. 2005; 101(6): 1849-57. 
[7] Zhang Y, Wong KC. Anesthesia and postoperative shivering: its etiology, treatment andprevention Acta Anaesthesiol Sin. 1999; 37(3): 115- 20 .

[8] Buggy DJ, Crossley AW. Thermoregulation, mild perioperative hypothermia and postoperative shivering. Br J Anesth. 2000; 84(5): 615-28.

[9] Kiekkas P, Poulopoulou M, Papahatzi A, Souleles P. Effects of hypothermia and shivering on standard PACU monitoring of patients. AANA J. 2005; 73(1): 47-53.

[10] Miller RD (eds). Anesthesia, 5th ed. Philadelphia: Churchill Livingstone; 2005.

[11] De Witte JL, Kim JS, Sessler DI, Bastanmehr H, Bjorksten AR. Tramadol reduces the sweating vasoconstriction and shivering thresholds. Anesth Analg. 1998; 87(1): 173-9.

[12] Iqbal A, Ahmed A, Rudra A, Wankhede RG, Sengupta S, Das T, et al. Prophylactic Granisetron Vs Pethidine for the Prevention of Postoperative Shivering: a Randomized Control Trial. Indian J Anaesth. 2009; 53(3): 330-4.

[13] Wrench IJ, Cavill G, Ward JE, Crossley AW. Comparison between alfentanil, pethidine and placebo in the treatment of postanaesthetic shivering. Br J Anaesth 1997; 79(4): 541-2.

[14] Terasako K, Yamamoto M. Comparison between pentazocine, pethidine and placebo in the treatment of post-anesthetic shivering. Acta Anaesthesiol Scand 2000; 44(3): 311-2.

[15] .Pazoki Sh, Noroozi A, Shadman AH. Comparison effect of different doses of Ketamine with Pethedine in reducing postoperative shivering after cesarean section. Arak Medical University Journal. 2009; 12(2): 9-16. [Persian]

[16] Khoshrang H, Parvizi A, Haddadi S, Heidarzadeh A.Comparing the Effect of Pethedine, Dexamethasone andPlacebo on Preventing Postoperation Shivering. Zahedan Journal of Research in Medical Sciences (Tabib-e-Shargh). 2007; 9(3): 155-61. [Persian]

[17] Sharma DR, Thakur JR. Ketamine and shivering. Anaesthesia 1990; 45(3): 252-3.

[18] Dal D, Kose A, Honca M, Akinci SB, Basgul E, Aypar U. Efficacyof prophylactic ketamine in preventing postoperative shivering. Br J Anaesth 2005; 95(2): 189-92.

[19] Al-Khaled H, Al-Kaabneh A. Intraoperative ketamine for the prevention of shivering posttrans urethral resection of prostate. Journal Royal Medical Service. 2006.13 (2): 30-3.

[20] Begum R, Islam R, Sarker PC, Karmakar KK, Alam AM. Prophylactic Use of Ketamine Hydrochloride for Prevention of Post OperativeShivering. Journal of the Bangladesh Society of Anaesthesiologists. 2008; 21(1):29-35.

[21] Talebi H, Kamali A, Yazdi B, Salehjafari N, Reihani Z, Hendodari N, et al. Comparing the efficacy of low dose ketamine versus pethidine in controlling shivering after tonsillectomy surgery. Anesthesiology and Pain Official Journal of ISRAPM. 2012; 2(6): 25-29. [Persian]

[22] Gecaj-Gashi A, Hashimi M, Sada F, Salihu S, Terziqi H. Prophylactic ketamine reduces incidence of postanaesthetic shivering. Niger J Med 2010; 19(3): 267-70.

[23] Norouzi M, Doroodian MR, Salajegheh S. Optimum dose of ketamine for prevention of postanesthetic shivering; a randomized double- blind placebo-controlled clinical trial. Acta Anaesthesiol Belg 2011; 62(1): 33-6.

[24] Hosseinzadeh H, Aidi M, Kolahdozan Kh. Comparision of efficacy of two methods for post oprating shivering (Pethidin \& Doxapram) in increasing the arterial oxygen saturation (SaO2). Pharmaceutical Sciences. 2003; 9(1): 29-37. [Persian]

[25] Rafiei MR, Hashemi SJ, Davodabadi AH, Adibhajbaghri M. The Study of Effects of Tramadol and Pethidine for Post Operative Shivering After Spinal Anesthesia for Inguinal Hernia Repair in Shahid Beheshti Hospital of Kashan During 18 Months. Iranian Journal of Surgery. 2006; 14(2): 0-0. [Persian]

[26] Javaherforoosh F, Pipelzadeh M, Namazi M. Effect of Oral Clonidine on Post Operative Nausea and Vomiting in Gynecological Laparoscopic Surgery. Armaghane-danesh, Journal of Yasuj University of Medical Sciences. 2008; 13(2): 19-27. [Persian]

[27] Entezariasl M, Isazadehfar KH, Mohammadian A, Khoushbaten M. Comparison the effect of ondansetron and meperidine in the prevention Of postoperative shivering after general anesthesia. Journal of Iranian Society Anaesthesiology and Intensive Care. 2008; 30(62): 23-32.

[28] . Khosravi A, Moein Vaziri MT. Effect of Dexamethasone on reducing postoperative shivering. Journal of Iranian Society of Anaesthesiology And Intensive Care. 2002; 21(35-36): 17-21.

[29] Heidari SM, Rahimi M, Soltani H, Hashemi SJ, Shabahang S. Premedication with oral tramadol reduces severity of postoperative shivering After general anesthesia. Adv Biomed Res. 2014; 3: 64.

[30] Yousuf B, Samad K, Ullah H, Hoda MQ. Efficacy of tramadol in preventing postoperative shivering using thiopentone or propofol as induction agent: A randomized controlled trial. J Anaesthesiol Clin Pharmacol. 2013; 29(4): 521-5.

[31] Jabbary Moghaddam M, Ommi D, Mirkheshti A, Dabbagh A, Memary E, Sadeghi A, Yaseri M. Effects of clonidine premedication upon Postoperative shivering and recovery time in patients with and without opium addiction after elective leg fracture surgeries. Anesth Pain Med. 2013;2(3): 107-10

[32] Entezariasl M, Isazadehfar K. Dexamethasone for prevention of postoperative shivering: a randomized double-blind comparison with pethidine. Int J Prev Med. 2013; 4(7): 818-24.

[33] Kim YS, Kim YI, Seo KH, Kang HR. Optimal dose of prophylactic dexmedetomidine for preventing postoperative shivering. Int J Med Sci. 2013; 13; 10(10): 1327-32.

[34] Shoar S, Esmaeili S, Khorgami Z, Naderan M, Shoar N. Efficacy of acupuncture in prevention of postoperative anaesthesia-related shivering. Acupunct Med. 2013; 31(1): 120-1.

[35] Entezari Asl M, Isazadehfar Kh, Akhavanakbari G, Khoshbaten M. The effect of ondansetron in prevention of postoperative shivering after general anesthesia in gynecological surgery. Iran Red Crescent Med J. 2012; 14(5): 316-7.

[36] Asl ME, Isazadefar K, Mohammadian A, Khoshbaten M. Ondansetron and meperidine prevent postoperative shivering after general anesthesia. Middle East J Anesthesiol. 2011; 21(1):67-70. 